\title{
Research Status and Development of Corrosion Detection Technology in Buildings
}

\author{
Hongzhou Hui ${ }^{1, a}$, FangHe ${ }^{2, b}$, Hongwei Ren ${ }^{3, c},{ }^{*}$, Lei Qin ${ }^{4, d}$ \\ ${ }^{1,2,3,4}$ School of automation and electrical engineering, University of Jinan, Ji'nan City, \\ Shandong Province, china,

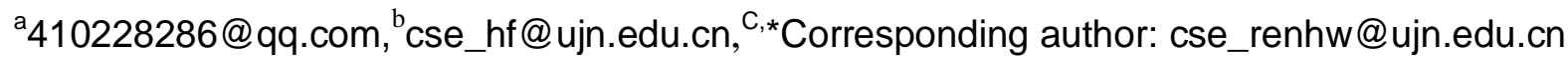 \\ dcea_qinl@ujn.edu.cn
}

Key words: concrete, steel corrosion, electrical tomography, nondestructive testing.

Abstract:This paper discusses the significance and research status of steel corrosion detection. This paper briefly analyzes several important detection methods and their application characteristics. The advantages and disadvantages of the present research methods are discussed. It puts forward the necessity of analyzing nondestructive testing technology, and sumsup the methods of nondestructive testing. Finally, a corrosion detection method based on electrical tomography was proposed.

\section{Introduction}

Reinforced concrete materials become aging in the natural environment and the use of conditions, with the passage of time. The corrosion of steel is the most direct and the most important reason for the deterioration of the durability of concrete structure, especially under the action of chlorine and wet dry environment. The durability of concrete structure in our country is very serious. The research on the durability of reinforced concrete structure is particularly important. If the failure of the structure caused by steel corrosion cannot be found early, cannot take effective remedial measures in time, then we will spend a year on the huge investment in civil engineering. We will suffer a great loss. Detection of steel corrosion is particularly important.

\section{Research status of corrosion detection technology}

At present, the most important methods of steel corrosion nondestructive testing generally include the following 3 aspects: analytical method, physical method and electrochemical method.[1] Analysis is according to the actual diameter of steel bar, the protective layer thickness, concrete strength, carbonation depth, penetration depth and $\mathrm{Cl}$ content, the number of cracks and the width of the data, to consider the environmental situation andthe corrosion degree of components; Physical methods are mainly determined by changes induced by steel corrosion resistance, heat conduction, electromagnetic, acoustic wave and the spread of other physical properties to reflect the corrosion condition. Electrochemical detection methods include: half cell method, concrete resistivity method, linear polarization method, etc..

\section{half cell method}

Half cell potential method is one of the most commonly used detection technology. From the perspective of the electrochemical, corrosion surface will form independent of anode and cathode zones . Voltage meter reading is measured by the potential position of steel bars. After collecting a 
large amount of data on the building surface, we can find the anode and cathode area, so as to determine the structure of the reinforcement corrosion of the site[2].

The test equipment is the United States JAMES company's production of steel corrosion detector GECOR6. The device has three main components, the host and two independent sensors..

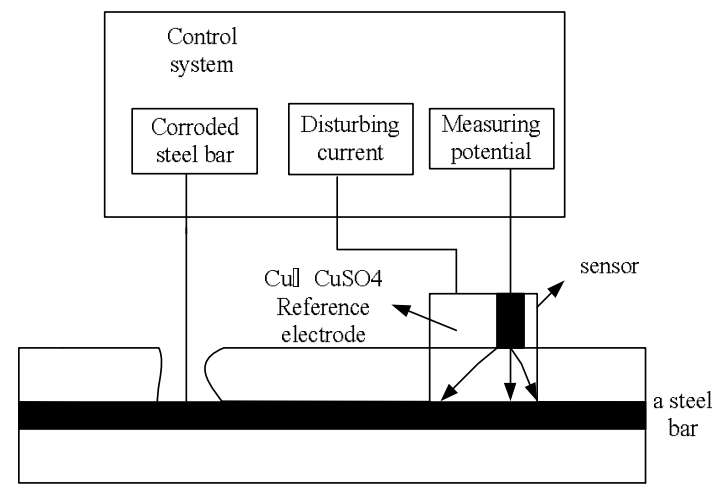

Fig .1. Principle and main component of the potential

In the project, the potential test is carried out according to the following steps:

The position of reinforcing steel bar is found by using the steel bar locating instrument and then use the drill to hole the surface of the steel bar, in order to ensure accuracy of test results. For each measuring point, at least two steel bars are exposed as working electrode,then use the high impedance voltage meter detecting the potential difference between them. Only when the potential difference is less than $1 \mathrm{~m} \mathrm{~V}$, the detection results are reliable. The following table1 shows the criteria for judging the corrosion of steel bars.

Table 1 The criteria for judging the corrosion of steel bars.

\begin{tabular}{|c|c|c|}
\hline & potential [mv] & corrosion degree \\
\hline 1 & $0 \sim-200$ & Corrosion rate 5\% or no corrosion \\
\hline 2 & $-200 \sim-350$ & $\begin{array}{c}\text { Theprobabilityof } \\
\text { reinforcing steel bar is } 50 \%\end{array}$ \\
\hline 3 & $<-350$ & $\begin{array}{c}\text { The probability of corrosion of the } \\
\text { steel bar is } 95 \% .\end{array}$ \\
\hline
\end{tabular}

\section{linear polarization method}

The linear polarization device Gecor 6 is applied to give a small disturbance current to the concrete. Testing the corresponding potential changes of the corrosion body $\Delta \varphi$. To obtain the Ratio of potential change and current change $R_{p} \cdot R_{p}$ is thepolarization resistance. The current density of corrosion of steel bar is obtained in accordance with the basic formula (Stern-Geary formula)[3] of the linear polarization method.

$$
I / \eta=i_{\text {corr }} \bullet\left[\frac{2.303}{b_{a}}+\frac{2.303}{b_{c}}\right]=\frac{1}{R_{p}}
$$




$$
\begin{aligned}
& R_{P}=\frac{\Delta \phi}{\Delta \mathrm{I}} \\
& i_{\text {corr }}=\frac{B}{R_{p} \bullet A}
\end{aligned}
$$

The corrosion current density criterion for judging the corrosion of steel bar is given in the table 2 .

Table2 The relationship between corrosion current density and corrosion of steel bar.[4]

\begin{tabular}{|l|l|l|l|l|}
\hline $\begin{array}{l}\text { current } \\
\text { density } \\
{\left[\mathrm{UA} / \mathrm{cm}^{2}\right]}\end{array}$ & \multicolumn{1}{|c|}{$0.1<\mathrm{I}_{\text {corr }}<$} & $0.5<\mathrm{I}_{\text {corr }}<1$ & $\mathrm{I}_{\text {corr }}>1$ \\
\hline $\begin{array}{l}\text { Corrosion } \\
\text { status }\end{array}$ & Passive state & $\begin{array}{l}\text { Slight } \\
\text { corrosion }\end{array}$ & $\begin{array}{l}\text { Mediumcorros } \\
\text { ion }\end{array}$ & $\begin{array}{l}\text { severely } \\
\text { corrode }\end{array}$ \\
\hline
\end{tabular}

\section{Concrete resistivity method}

The corrosion rate of steel bar is dependent on the supply of oxygen to the cathode reaction, and also dependent on the resistivity of the concrete. It determines the transfer rate of ions in the cathode and anode, and the resistivity of concrete depends on the microstructure of concrete and water saturation. [5]Therefore, the greater resistivity, the lower ion electron flow, the lower the corrosion rate.

The method of measuring the resistivity of concrete is disk method, two- electrode method and four-electrode method. Commonly used methods are four-electrode method, see figure 2. This method does not need to make the measurement instrument and steel bar connection. The measurement time is short, so it is suitable for long-term follow-up observation of the corrosion of steel in concrete.

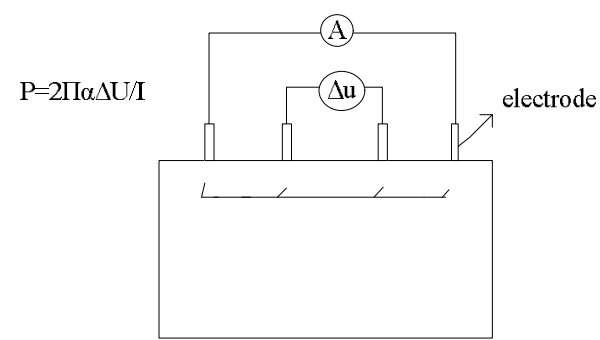

Fig.2. four schematic diagram of the resistivity of concrete

The detection of corrosion rate of steel bars is a qualitative test. The corresponding relationship between resistivity and corrosion rate of concrete is given in the following table3.[6] 
Table 3The evaluationcriterion of the corrosion degree of steel bar with concrete resistivity.

\begin{tabular}{|c|c|c|c|}
\hline \multicolumn{2}{|c|}{ Four electrode method } & \multicolumn{2}{c|}{ Two electrode method } \\
\hline resistivity & Corrosion rate & resistivity & Corrosion rate \\
\hline$>20$ & low & $>100$ & M icro corrosion \\
\hline $10 \sim 20$ & secondary & $50 \sim 100$ & Low corrosion rate \\
\hline $5 \sim 10$ & fast & $10 \sim 50$ & Medium corrosion \\
\hline$<5$ & Very fast & $<10$ & Has nothing to do with \\
\hline
\end{tabular}

\section{Development direction of corrosion detection technology}

The principle of the forward problem is to solve the electric potential or current distribution of the electromagnetic field. The premise is that the distribution of electrical properties (conductivity, dielectric constant, etc.) and the boundary conditions (external excitation) of the sensing medium are known. The inverse problem is to obtain the sensitive field of medium distribution. The precondition is that the information is based on the boundary excitation.

For electrical tomography, we should first establish the mathematical model of the sensitive field, which can be introduced by the Maxwell equations of the electromagnetic field.[7] Its differential form is shown below.

$$
\begin{aligned}
& \nabla \bullet D=\rho \\
& \nabla \times E=-\frac{\partial B}{\partial t} \\
& \nabla \bullet B=0 \\
& \nabla \times H=J+\frac{\partial D}{\partial t}
\end{aligned}
$$

Image reconstruction algorithms include: Linear back projection algorithm, Tikhonov regularization algorithm, Landweber iterative algorithm, conjugate gradient algorithm and so on.[8] The experimental measurement system is shown in Fig3. The system uses the finite element simulation software 3.5A COMSOL to establish the simulation model, and uses 2010b Matlab and COMSOL to carry on the simulation. The system adopts the single excitation measurement mode, that is, the same time, only one electrode is applied to the excitation signal, and the other electrodes are grounded. 


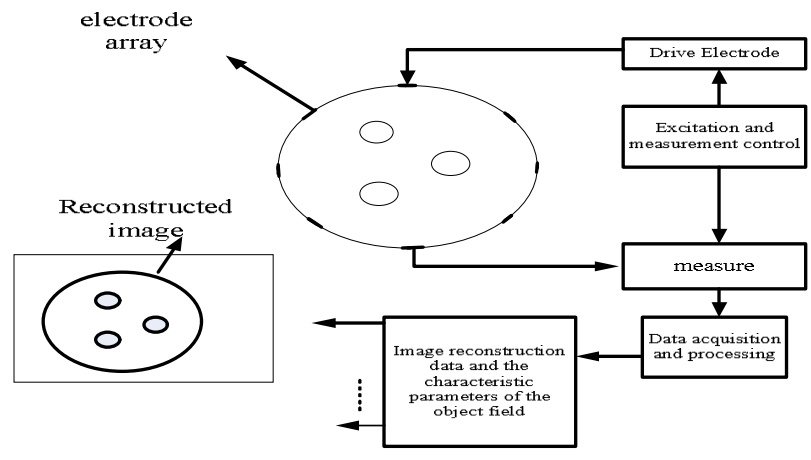

Fig.3.ET System diagram

\section{Concluding remarks}

In this paper, the electrochemical and physical methods for nondestructive testing of steel corrosion in reinforced concrete structures are summarized. Each of these methods has its characteristics, but there is a certain gap with respect to the practical requirements of the project. At last, the paper introduces the detection technology based on Electrical tomography, which puts forward a new idea of steel corrosion detection, and makes a useful exploration in this area. The measuring method of electrical tomography is a reflection of the integrity of the component, which can be used to detect the corrosion damage of steel bars, which is of great reference value to the overall structure of the component. Therefore, it is of great significance to further research on this method.

\section{Reference}

[1] Yang Guang, a patron. The detection of reinforcement corrosion in concrete [J]. Shanxi building, 2005

[2] He Zhichuan. Study on Corrosion of steel in concrete by half cell potential method [D]Harbin Institute of Technology, 2008

[3] Zhu Xiaoe. Experimental study on Corrosion of steel in concrete by linear polarization method [D]. Shantou University, 2006

[4] Luo Gang, Shi Yang Kang. Nondestructive testing method for the amount of steel corrosion in reinforced concrete members [J]. Fujian architecture, 2002,

[5] Wei Xiaosheng, Xia Yuying, Wang Yanwei. Evaluation of chloride ion penetration in concrete by electrical resistivity method [J]. Journal of Huazhong University of Science and Technology (Urban Science Edition), 2008

[6] Ying Wenwu. nondestructive testing technology in concrete structure of [D]. Zhejiang University, 2011

[7] Li Shouxiao. Electrical imaging algorithm and gas solid two phase flow study [D]. Tianjin University, 2012

[8] Wang Pitao, Wang Huaxiang, sun Benyuan. Based on the internal array electrode ect / ERT dual modality imaging $[\mathrm{J}]$. Tianjin University Journal (Natural Science and engineering and Technology Edition) 2015 